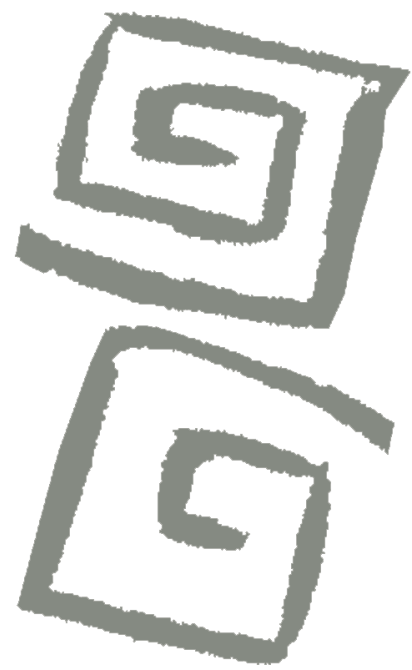

\title{
El desafío de la descolonización del conocimiento: el Diccionario de favelas Marielle Franco
}

\author{
The challenge of decolonizing knowledge: the Marielle \\ Franco Favela Dictionary
}

Sonia Fleury ${ }^{1}$, Clara Polycarpo², Palloma Menezes ${ }^{3}$, Marcelo Fornazin ${ }^{4}$

${ }^{1}$ Doctora en Ciencias Políticas. Investigadora, Centro de Estudos Estratégicos de Presidência, Fundação Oswaldo Cruz. Coordinadora, Dicionário de Favelas Marielle Franco, Rio de Janeiro, Brasil. $\bowtie$ (iD)

${ }^{2}$ Magíster en Ciencias Sociales. Investigadora, Dicionário de Favelas Marielle Franco, Instituto de Comunicação e Informação Científica e Tecnológica em Saúde, Fundação Oswaldo Cruz, Rio de Janeiro, Brasil. $\triangle$ (iD)

${ }^{3}$ Doctora en Sociología. Docente, Instituto de Estudos Sociales e Políticos, Universidade do Estado do Rio de Janeiro, Rio de Janeiro, Brasil. $\square$ (iD)

${ }^{4}$ Doctor en Administración. Investigador, Escola Nacional de Saúde Pública, Fundação Oswaldo Cruz. Profesor, Departamento de Ciência da Computação, Universidade Federal Fluminense. Rio de Janeiro, Brasil. $\triangle$ iD
RESUMEN Los sectores dominantes de la sociedad describen las favelas a partir de definiciones negativas a priori, que han sido cuestionadas por diversos actores colectivos. A partir de una iniciativa conjunta de la comunidad académica y quienes residen en las favelas, se crea el Diccionario de Favelas Marielle Franco como una plataforma en línea que, a través de la construcción colectiva del conocimiento, busca difundir diferentes narrativas sobre estos territorios y sus poblaciones. En este artículo, discutimos cómo se produjeron los acuerdos y divergencias entre el conocimiento de la comunidad académica, activistas y habitantes de barrios marginalizados; y presentamos la trayectoria de la construcción del Diccionario, que busca superar tensiones y así incorporar otros lenguajes y registros capaces de sustentar las producciones y memorias de las favelas.

PALABRAS CLAVES Favelas; Espacios Urbanos; Estudios Decoloniales; Brasil.

ABSTRACT Dominant social groups describe favelas based on negative stereotypes, which are increasingly being challenged by various collective actors. Originating from a collaborative effort carried out by academics and favela residents, the Marielle Franco Favela Dictionary is an online platform that aims to spread alternative narratives regarding these territories and their populations through collective knowledge building. This article discusses the common ground and points of contention regarding the different forms of knowledge held by academics, activists, and favela residents. Furthermore, we reconstruct the trajectory of the Dictionary's creation, and in so doing overcome certain tensions and incorporate other languages and registers able to support the production of memory in favelas.

KEY WORDS Favelas; Urban Area; Decolonial Studies; Brazil. 


\section{INTRODUCCIÓN}

El proceso de producción de conocimientos está, casi siempre, permeado por obstáculos que se presentan tanto desde el lenguaje y las formas de expresión/manifestación del pensamiento, como desde las relaciones de poder perpetuadas por la colonización de saberes y grupos. Por lo tanto, la realidad y los sujetos se producen $-y$ también se disputan- a través de acuerdos y desencuentros de historias y narrativas. En este sentido, el Diccionario de favelas Marielle Franco (www.wikifavelas.com.br) nace de diversos encuentros que ponen en evidencia los múltiples desencuentros que, como parte de la reproducción de las relaciones sociales y del intercambio de bienes simbólicos, se imponen socialmente a la producción de conocimientos y a las prácticas políticas. Como un caso particular y una experiencia en curso, el Diccionario de favelas Marielle Franco se inserta en el proceso de producción colectiva de conocimientos $y$, fundamentalmente, trata del encuentro/desencuentro entre quienes estudian diferentes aspectos de la temática urbana y militan por los derechos humanos y sociales de la ciudadanía, y quienes lideran las favelas y reivindican su lugar de sujetos en la producción de conocimientos y de prácticas emancipadoras. En una mezcla de denuncia -de la objetificación y la subalternización a la que siempre fueron sometidos por la academia- $y$ de afirmación de sus potencias y saberes, se fueron construyendo relaciones de confianza que sustentaron alianzas y coaliciones, sin ignorar las brechas sociales persistentes. Se trata, por lo tanto, de analizar y reflexionar sobre un proceso en curso, de manera de aprender y aportar con su experiencia.

Como presupuesto, reconocemos que la fragmentación imperante en la producción académica fracciona el conocimiento en múltiples áreas disciplinares que imposibilitan comprender fenómenos sociales complejos, como la realidad de las favelas y áreas periféricas brasileñas, estudiadas en este caso desde diversas perspectivas como la urbana, histórica, antropológica, sociológica, de políticas públicas, económica, lingüística, etc. Por otro lado, la jerarquización de los saberes construye una pirámide en la cual las vivencias, los saberes populares, las prácticas sociales e incluso la producción académica proveniente de centros culturales de las favelas han sido jerárquicamente inferiorizados en función de las limitaciones para su circulación y difusión en ambientes intelectualmente reconocidos, como las universidades.

La difusión de las tecnologías de la información en estas últimas décadas ha llevado a la situación contradictoria de, por un lado, democratizar el acceso y permitir, por ejemplo, una rica producción de audiovisuales $y$, por otro lado, aumentar el abismo tecnológico intergeneracional e interclases, ya que tales tecnologías circulan en el mercado con fines de lucro, pero han sido escasamente provistas o reguladas por el poder público. Las últimas políticas públicas orientadas a los territorios y poblaciones de las favelas del estado de Rio de Janeiro fueron las Unidades de Policía Pacificadora (UPP), que se transformaron en un proceso de militarización ${ }^{(1)}$ en el que la policía utilizó la tecnología para el control social, mientras que los habitantes la utilizaron para denunciar las arbitrariedades de la policía.

Paradójicamente, la ocupación militar de las favelas generó espacios de circulación de personas y discursos, que permitieron nuevos encuentros entre diferentes militancias y el reconocimiento de insurgencias que se manifestaban en una gran variedad de colectivos y organizaciones locales, que levantaban la bandera de los derechos de ciudadanía y no aceptaban el lugar que la sociedad los había destinado.

Reconocer ese proceso de subjetivación, de la existencia de un sujeto que enuncia su discurso, nos llevó a pensar en la necesidad de crear un instrumento que, a pesar de todos los desencuentros mencionados, permitiera que diferentes discursos se encuentren y confronten en un espacio virtual, colectivo, común. Sin pretensiones de superar las discrepancias, sino más bien como un espacio en el cual diferentes sujetos pudieran ejercer su capacidad de expresión. Así surge el Diccionario de favelas Marielle Franco. 
En este artículo, buscamos explicitar los fundamentos teórico-filosóficos que orientaron la construcción del Diccionario de favelas Marielle Franco, como una experiencia en desarrollo, aunque tal identificación solo haya sido posible a posteriori, ya que se dio en el proceso de producción colectiva que es, por naturaleza, inacabado. Realizar el esfuerzo de nominar tales fundamentos fue necesario para confrontarlos con la práctica, lo que nos permitió identificar diferentes etapas en ese proceso de construcción. En este sentido, el artículo se presenta a partir de lo que entendemos como etapas de implementación de esta experiencia, lo que explicita en sí sus desafíos como producción colectiva de conocimientos.

En la primera sección, enunciamos los presupuestos que orientaron el proyecto del Diccionario de favelas y cómo se materializó en una plataforma wiki. Luego, relatamos la primera etapa de este proceso, la implementación del Diccionario de favelas -WikiFavelas-, en la que se confrontaron los presupuestos con las dificultades encontradas en la práctica. En la segunda sección, abordamos los desafíos, avances, paradojas y contradicciones enfrentados, se explicitan las transversalidades y tensiones que impone la realidad social. La tercera sección analiza cómo enfrentar estas tensiones, lo cual estimuló la búsqueda de alternativas y configuró una segunda etapa orientada a motivar, producir y difundir los conocimientos. Se buscaron formas de expresión de los colectivos de las favelas en Internet, lo que exigió cambiar la tecnología de la plataforma para incorporar, además de texto escrito, imágenes y videos, música y poesía, acercando el Diccionario a la tradición oral que predomina en las favelas. Al mismo tiempo, se fortaleció el poder del equipo de investigación del Diccionario de favelas en la búsqueda activa de producciones de las favelas. La tercera etapa se incluye en la cuarta sección dedicada al coronavirus en las favelas, en la que se describe cómo la pandemia y las demandas de los actores de las favelas toman el Diccionario de favelas, y se invierte el proceso de demanda por parte del equipo de investigación, que pasa a interactuar y organizar el material enviado por los productores de las favelas. En esa etapa, que aún está en curso, el Diccionario de favelas excede la plataforma y pasa a tener una intervención e incidencia políticas a través de transmisiones en vivo por las redes sociales, en las que líderes de las favelas relatan cómo enfrentan la pandemia y cómo es el cotidiano de los vecinos. Esto requirió una mayor inversión en el área de comunicación y divulgación y en la producción de datos, mapas y cartografías, de la que surgieron nuevas alianzas, coaliciones y articulaciones. En la sección final de las conclusiones, reflexionamos sobre el contenido político de ese proceso y sobre su sustentabilidad.

\section{FUNDAMENTOS PARA UNA PROPUESTA DE DESCOLONIZACIÓN DE SABERES}

Desde mediados del siglo XX, las discusiones sobre las favelas, como un campo de estudios específico, están presentes en contribuciones de las áreas de ciencias sociales y urbanismo, aunque tales conocimientos se encuentran fragmentados, y la producción de saberes de las propias poblaciones de las favelas y áreas periféricas sigue siendo, en su mayoría, desconocida. La dispersión de los conocimientos sobre las favelas y su fragmentación en innumerables campos disciplinarios sirvieron de estímulo inicial para pensar un proyecto, ideado por Sonia Fleury, en 2014, que fuera capaz de aunar, no solo la producción académica-cuyas tesis y monografías raramente vuelven a quienes fueron entrevistados en las favelas- sino además otras formas de conocimientos producidos por las propias personas que habitan esos territorios.

El proyecto pasó a llamarse Diccionario de favelas Marielle Franco como un tributo a la intendenta del Municipio de Rio de Janeiro cruelmente asesinada, junto a su chofer Anderson Gomes, el 14 de marzo de 2018. A varios años de perpetrado el brutal crimen, la sociedad, su familia y su electorado aún desconocen quién mandó a matarla y por qué. 
Entre las pocas certezas, sabemos que fue un crimen político. En 2016, a los 37 años y con 46.502 votos, fue la quinta legisladora más votada de la ciudad y la segunda mujer con más votos, pero no pudo concluir su mandato de cuatro años. La incidencia política de Marielle no comenzó en la Cámara de Legisladores de Rio de Janeiro, ni concluyó con su muerte. El Diccionario de favelas cuenta con un artículo que describe la vida y la trayectoria política de Marielle Franco ${ }^{(2)}$.

En el prefacio del libro de Fanon, Los condenados de la tierra, al hablar sobre la colonización, Sartre afirma que "los primeros disponían del verbo, los otros lo tomaban prestado"(3). El objetivo del Diccionario de favelas Marielle Franco es crear un espacio plural y horizontal, en el que diferentes productores de saberes sobre las favelas puedan hacer uso del verbo. Buscaron callar a MarieIle, que representaba la esperanza de nuevas prácticas políticas que permitieran la representación de mujeres negras, de las favelas y del colectivo LGBTQI +, por eso, valorizar esas voces es también conservar su legado.

La propuesta de descolonización del conocimiento sobre las favelas está basada en la búsqueda de superación del mundo compartimentado, rompiendo las líneas divisorias establecidas como marcas territoriales de dominación ${ }^{(4)}$. En este artículo, optamos por considerar los conceptos de "descolonización" y "decolonización" para dar cuenta tanto del proceso histórico de superación del colonialismo, en su sentido clásico, como de la posición que quebranta la colonialidad del saber y del poder presente incluso en el período poscolonial ${ }^{(5)}$. La demarcación asfalto/ favela, por ejemplo, implica una estrategia constante de ejercicio de poder definida por Foucault( ${ }^{(6)}$ como gobernamentalidad, para referirse a "esa forma bien específica, aunque muy compleja de poder, que tiene por blanco central la populación, por forma mayor del saber la economía política y por instrumento técnico esencial los dispositivos de seguridad".

El Diccionario de favelas Marielle Franco se centra, por lo tanto, en la creación de un espacio virtual que no esté demarcado por las líneas divisorias asfalto/favela, a las cuales están asociadas otras polarizaciones como orden/desorden, legal/ilegal, blanco/negro, incluidos/excluidos. O sea, la sustitución de la construcción del otro como compartimentación en dirección a una ética de la pluralidad y alteridad, en el interior de las luchas por la construcción de una sociedad democrática e inclusiva.

Como la población de las favelas y de áreas periféricas es mayoritariamente negra y mestiza, resulta necesario entender cómo opera el elemento raza en el proceso de subalternización y exclusión, que potencia la cuestión territorial. Las relaciones de poder se reproducen al asociar la idea de raza con las formas de control y explotación del trabajo, colonialidad que Quijano identifica como originaria de las Américas: "Ese elemento fundacional de la explotación colonial permitía imponer una división racial del trabajo $^{\prime \prime(7)}$. Así, la cuestión racial se impone como un eje central en la producción del Diccionario de favelas, al entender, como proponía Guerreiro Ramos, que la sociología brasileña solo dejará de estar colonizada cuando se conecte con su realidad y asuma su devenir negro como cuestión central de investigación ${ }^{(8)}$. Mbembe explica que la raza es una moneda icónica, que aparece en un comercio de imágenes:

Es una moneda que tiene la función de convertir aquello que se ve o aquello que se elige no ver en una especie o símbolo dentro de una economía general de los signos y de las imágenes que se intercambian, circulan, se les atribuye o no valor, y que autorizan una serie de juicios y de actitudes prácticas.(9)

Tornar visible aquello que está oculto, como el racismo estructural de la sociedad brasileña, es una perspectiva descolonizadora que valida el conocimiento basado en relaciones sociales que son eludidas por la epistemología dominante ${ }^{(10,11)}$. Dividir la ciudad entre asfalto y favela es una división racial, que tiene como consecuencia la prohibición simbólica 
y coercitiva de la circulación de los cuerpos negros en el asfalto, más allá del circuito de trabajo. Los cuerpos negros, cuando rompen esos límites, siempre serán sospechosos.

Sin embargo, en el proceso de dominación se imponen otras transversalidades, que atraviesan, incluso, las poblaciones y territorios de favelas y periferias. Para explicar la persistencia de la desigualdad en el capitalismo brasileño, territorio de la colonialidad, Lélia Gonzalez considera que, además de la explotación económica, resulta necesario conjugar racismo y sexismo, como se evidencia al constatar que "los más bajos niveles de participación en la fuerza de trabajo, coincidentemente, pertenecen exactamente a las mujeres y a la población negra"(12). O sea, que no se puede descolonizar sin despatriarcalizar ${ }^{(13)}$.

La naturalización de la dominación por medio de la división sexual es parte de una violencia simbólica que se materializa en los cuerpos y habitus. Bourdieu ${ }^{(14)}$ ve en el sexismo un esencialismo como otros -racismo, étnico o clasista- y le atribuye a la naturaleza biológica diferencias sociales históricamente construidas. Por lo tanto, lo considera un esencialismo más arraigado y más difícil de cambiar.

Así, construimos el andamiaje teórico que fundamenta la praxis de la elaboración e implementación del Diccionario de favelas Marielle Franco y nos posicionamos en el debate del proceso de descolonización de saberes. Sin embargo, la mera puesta en marcha de un instrumento que permita la divulgación de discursos de la población de las favelas, no sería capaz de provocar un proceso de transformación en la propia subjetividad de esas poblaciones. $\mathrm{O}$ sea, el sujeto antecede al verbo, el sujeto preexiste al discurso, aunque se constituya en las prácticas y luchas materiales y simbólicas, al afirmar su consciencia al interior de la tensión permanente entre determinación social y afirmación de la libertad individual y grupal ${ }^{(15)}$.

La creación y la viabilidad del Diccionario de favelas pueden ser entendidas como parte de un proceso más general -que podemos observar y compartir en las investigaciones en las favelas y en la bibliografía reciente-denominado por $\mathrm{D}^{\prime}$ Andrea ${ }^{(16)} \mathrm{como}$ la emergencia del sujeto periférico. Se trata de la afirmación y positivación de la identidad de una parte de la juventud de las favelas y áreas periféricas, construida en torno de la polarización entre carencias y potencias; lugar desde el cual, a través de manifestaciones culturales y estéticas, problematizan cuestiones de clase, raza y género. Estos temas aparecen en diferentes luchas y formas culturales, tales como letras de música, en una estética propia (hip-hop y funk, poesía y danza), como se manifiesta en las batallas de slams y de baile, entre otras.

\section{Construir un ambiente abierto, gratuito y común: las wikifavelas}

El Diccionario de favelas Marielle Franco se abrió oficialmente a la participación pública en abril de 2019, a través de un evento de lanzamiento realizado en la Biblioteca de la Fundación Oswaldo Cruz, en Rio de Janeiro. El evento reunió a un grupo de investigadores y líderes sociales para discutir las posibilidades que se abren a partir de un trabajo en red, que busca agrupar y compartir el conocimiento producido sobre y desde las favelas, a partir de una colaboración mediada por tecnologías digitales. Los homenajes a la intendenta carioca están disponible en el Diccionario de favelas ${ }^{(17)}$.

En términos tecnológicos, el Diccionario de favelas está basado en una plataforma digital wiki, accesible a través del sitio www.wikifavelas.com.br, que define las reglas de acceso, colaboración e indexación de su contenido, entre otras cosas. Wikipedia fue la inspiración tecnológica del Diccionario de favelas, y desde el sentido común es vista como una enciclopedia libre y colaborativa, en la que cualquier persona puede realizar contribuciones. Sin embargo, Esteves y Cukierman ${ }^{(18)}$ mencionan que la voz de los diferentes actores tiene un peso distinto, y que el criterio que rige la jerarquía es propio de ese foro; es decir, la edición irrestricta puede ser regulada por tipos de autorización. 
Al considerar las limitaciones que planteaban las reglas de Wikipedia, se optó por crear una wiki propia para el Diccionario de favelas Marielle Franco: WikiFavelas. La diferencia respecto a Wikipedia, cuyos textos de múltiples autores se presentan como consensuales, el Diccionario de favelas se caracteriza por la pluralidad de puntos de vista, con texto autorales y explicitación de polémicas y divergencias, dentro de reglas de respeto a los valores democráticos. Esas opciones, políticamente justificables, representan, sin embargo, enormes desafíos para el equipo de tecnologías de la información, pues demandan soluciones originales.

La existencia de una red informal que reúna investigadoras e investigadores que se dedican a estudiar las favelas y líderes políticos y culturales de las favelas y de zonas periféricas de Rio de Janeiro, permitió que las y los intelectuales se movilizaran para discutir de forma conjunta el proyecto del Diccionario de favelas. Posteriormente, se institucionalizó un comité editorial, instancia de poder responsable de la definición de las reglas de participación, formulación de estrategias y movilización de participantes. Para la conformación del comité editorial se siguieron criterios de paridad entre intelectuales, miembros de organizaciones de las favelas y de la academia. Se constituyó un equipo multidisciplinario de investigadores, integrado por un grupo especializado en tecnologías de la información, responsable de la plataforma WikiFavelas, y otro grupo de científicos sociales responsables de los artículos, definidos como manifestaciones autorales sobre las favelas y presentados como páginas abiertas de una plataforma en línea.

Además de las dificultades planteadas por la interdisciplinaridad y por los desafíos tecnológicos, en las reuniones de concepción del Diccionario de favelas surgieron otras cuestiones vinculadas a la autoría y a la preservación del contenido. Con relación a la autoría, por ejemplo, el Diccionario de favelas cuenta con una licencia libre Creative Commons y no establece un derecho autoral individual. Se parte de la noción de que cada entrada del Diccionario es una construcción colectiva y que no puede ser reducida a una autoría única. Sin embargo, el consejo editorial estableció que aquellas personas que crean una entrada se las mencione como "autor/a original" en el encabezamiento del texto y otras personas con el rol de "colaborador/a registrado/a" pueden adicionar nuevas secciones a la entrada, o abrir una discusión, por medio de la cual presenten sus cuestionamientos y consideraciones. El rol de colaborador/a registrado/a lo puede cumplir cualquier persona que, de manera gratuita y libre, ingrese sus datos a la plataforma. De este modo, tiene libertad para crear entradas y/o iniciar discusiones. Al ser una plataforma abierta al público, incluso las personas que no estén registradas pueden acceder de forma libre al contenido. El registro es importante, justamente, para colaborar con la producción colectiva de conocimientos.

Los grandes temas enfrentados en esta primera etapa se relacionaron con la paradoja de proponer una nueva epistemología que contemplara los conocimientos producidos tanto por los grupos de investigación académicos como por quienes habitan las favelas, a través de un instrumento tecnológico que no es neutro con relación a la validación de los conocimientos producidos, dado que está mediado por la hegemonía del lenguaje escrito y, en este caso, tecnológico. Se realizaron grandes esfuerzos para motivar a posibles colaboradores de las favelas y área periféricas que, si bien se entusiasmaban con la propuesta, tuvieron dificultades para producir textos dentro de las reglas establecidas e introducirlos en la plataforma de WikiFavelas. Incluso, con la horizontalidad teóricamente propuesta en los talleres de presentación de la plataforma en diversas favelas, las relaciones entre el equipo de investigación y las personas que habitaban las favelas seguía siendo jerárquica y tutelar, y exigía además el dominio de la escritura y de las tecnologías de la información, dentro de una plataforma cuyas reglas habían sido definidas previamente por un selecto grupo. Más allá de los esfuerzos y de las relaciones personales, el contexto académico, impone un marco que intimida y coloca en posición de subalternidad a aquellas 
personas que vienen de las favelas. En el período de concepción del proyecto, la participación de los miembros del consejo editorial en la Escuela Brasileña de Administración Pública y de Empresas de la Fundación Getúlio Vargas (EBAPE-FGV) - una escuela cada vez más orientada a los negocios y las finanzas y distanciada de la temática de las favelasse tornaba cada vez más intimidatoria, dado que la arquitectura, la seguridad y la estética traducían un proyecto educacional elitista. Al proponer una producción colaborativa, plural y horizontal, en un contexto institucional y tecnológico altamente jerarquizado se generó una gran disconformidad. Los representantes de las favelas que formaban parte del consejo editorial comenzaron a exigir que las reuniones se realizaran en las propias favelas, y varios miembros del equipo presentaron el proyecto en diferentes centros culturales de las favelas. El cambio de la sede del proyecto a la Fundación Oswaldo Cruz, ubicada cerca de las favelas de Maré, Alemão, Manguinhos y Jacarezinho, atenuó parcialmente este problema, ya que la institución tenía varios trabajos en colaboración con favelas de la zona.

La motivación a colaborador en la primera parte del proyecto se realizó principalmente por medio de invitaciones realizadas por grupos de trabajo, además de reuniones en las favelas y talleres para que posibles colaboradores aprendieran a manejar y se apropien de los instrumentos de la plataforma. Se invitó a personas de la academia, habitantes de las favelas, activistas y de la gestión pública a escribir artículos a partir de un menú de temas propuestos. En el período 20172018 se invitó a 386 personas, de diferentes inserciones sociales, para proponer temas y, para abril de 2019, cuando el Diccionario de favelas se lanzó oficialmente, la plataforma ya contaba con 178 artículos sobre diversos temas vinculados a la propuesta. Actualmente, en 2021, existen aproximadamente 1.000 artículos en la plataforma.

A pesar del éxito alcanzado en la etapa inicial, quedaba claro que la dinámica para incentivar la colaboración estaba aún limitada a nuestras redes de contactos y de intereses, y resultaba claramente tendenciosa, lo que muestra que el equipo del Diccionario de favelas no había conseguido una adhesión exponencial de colaboradores, ni en las favelas ni en las universidades. Incluso habiendo podido incorporar un listado significativo de artículos en el Diccionario, los límites estaban claros tanto por parte de la producción académica como por la experiencia vivida, y era necesario encontrar formas de superar esas limitaciones de la etapa inicial. La existencia de una plataforma como dispositivo puesto a disposición de las poblaciones de las favelas, solo se torna relevante si nos cuestionamos respecto de los sujetos y cómo intervienen en la construcción o en la deconstrucción de los dispositivos ${ }^{(19)}$ en tanto red de relaciones sociales que unen a quienes producen la información, quienes permiten la circulación por medio de artefactos técnicos, quienes intervienen para facilitar su difusión, y quienes se apropian de la información.

Por supuesto, desde un inicio había apropiaciones discursivas, cuya circulación a través de este dispositivo amplificaron denuncias e insurgencias. En este caso, por ejemplo, se destaca el rol de los artículos sobre "chacinas" (matanzas), que comenzaron a relatar la historia de las vidas perdidas, en general de jóvenes negros víctimas de la brutalidad policial. La organización de los familiares de víctimas de estas matanzas y la necesidad de verbalizar, denunciar y mantener vivo el acontecimiento a través de actos, palabras, signos e imágenes "es también una forma radical de manifestarlo, como una epifanía"(9), ya que impide una segunda muerte, que es la de la identidad de los jóvenes muertos, a los cuales la policía designa como delincuentes muertos en combate.

\section{MOTIVAR ACTORES PARA LA PRODUCCIÓN Y DIFUSIÓN DE CONOCIMIENTOS}

Como ya fue mencionado, la plataforma $\mathrm{Wi}$ kiFavelas se propone quebrar paradigmas de producción de conocimientos, valorando la pluralidad en la construcción de saberes en 
un formato libre, interdisciplinario y abierto al público. Pero la propuesta de romper con las jerarquías de producción de conocimientos encontró barreras también en este formato, tanto en las dificultades técnicas anteriormente señaladas como en las dificultades para expresarse dentro del régimen represivo del colonialismo y del racismo ${ }^{(20)}$. ¿Quién va en realidad a compartir sus memorias en una plataforma abierta? Por otro lado, ¿quién va a considerar esos saberes como saberes legítimos? En este sentido, cabe retomar el cuestionamiento de Spivak ${ }^{(21)}$ : ¿se puede hablar desde la subalternidad? Además, ¿alguien puede hablar en lugar de la persona subalterna? ¿Cómo viabilizar un espacio que no reproduzca las violencias narrativas, epistemológicas y simbólicas que otorgan a las instituciones y a la ciencia moderna un carácter de superioridad? Estos son desafíos que, ante una disputa política y epistemológica, el Diccionario de favelas también debe enfrentar.

La producción y la reproducción de conocimientos están enmarcados en contextos culturales y políticos, en los que la colonialidad del saber y del poder transciende las particularidades del colonialismo histórico y no desaparece con la descolonización. El "epistemicidio"(10,11), por ejemplo, es un fenómeno que ocurre cotidianamente a través de la degradación de la autoestima que provocan el racismo y la discriminación en el cotidiano de jóvenes negros y de las periferias, tanto en las escuelas como en las instituciones de investigación, y se articula con la negación de la condición de sujetos de conocimiento a la población negra, a través de desvalorizar, ocultar o negar las contribuciones de la diáspora africana ${ }^{(22)}$. Esta es la realidad de una parte significativa, si no de la mayoría, de las personas que viven en las favelas y en áreas periféricas de todo Brasil, por lo que no pudieron apropiarse de sus historias y no pudieron compartirlas, quedando silenciadas.

A través de una perspectiva decolonial, el Diccionario de favelas problematiza el conocimiento considerado hasta entonces científico -centralizado en las universidades- y a los propios textos, que muchas veces desconectan a los sujetos del campo de acción para objetificarlos a través de otras versiones. La propia producción de la ciudad -fruto de tantos saberes y poderes oriundos de las prácticas modernas- también relega el conocimiento de las personas subalternas y que viven en las favelas. El derecho a la memoria y el derecho a la ciudad son principios fundamentales a ser también conquistados por la valoración de la epistemología de las favelas y periferias. Más allá de rescatar las epistemologías del sur, al haber sido una colonia europea en el pasado y periferia del capitalismo hoy, rescatar las epistemologías de las periferias de las ciudades modernas es parte de la lucha por la ciudadanía.

La estrategia inicialmente adoptada para la producción de los artículos partió de la definición de ejes de análisis sobre la realidad de las favelas y las periferias -Estado y Mercado, Sociabilidad y Cultura, Asociativismo y Memoria- organizados por los grupos de trabajo para invitar e incentivar la participación, junto a la realización de talleres en diferentes favelas y áreas periféricas para definir y redactar las entradas de los articulos. La organización en grupos de trabajo resultó útil para crear una forma de debate colectivo, sobre elecciones y reglas, aunque las temáticas sean, muchas veces, transversales a la división de los grupos. Sin embargo, la propia conformación de un grupo de trabajo sobre Asociativismo y Memoria, específicamente orientado a líderes de las favelas, y otro sobre Estado y Mercado orientado a estudiosos de políticas públicas, revela las dificultades de superar el epistemicidio y la jerarquización del conocimiento científico académico.

En el grupo de trabajo sobre Asociativismo y Memoria, participaron los territorios y centros culturales de favelas que contaban con representación en el Diccionario de favelas desde la formulación del proyecto, y que serían quienes darían inicio a la producción de otras entradas sobre, por ejemplo, el Complexo do Alemão, la favela Santa Marta, Cidade de Deus y el Complexo da Maré, en Rio de Janeiro. Luego, el Diccionario de favelas extendió sus colaboraciones hacia otros territorios, e invitó a personas para coordinar y producir artículos en las favelas Rocinha, 
Morro do Borel, Manguinhos y Acari, también en Rio de Janeiro, además de grupos de investigación de otras regiones del país. En suma, se expandió en forma de ondas concéntricas, como las que se forman al tirar una piedra en un lago.

Los temas prioritarios y la elección de autores individuales o colectivos, los definían quienes tenían a su cargo la coordinación de los centros culturales en cada uno de los territorios representados. La coordinación tenía total libertad para decidir sobre la elección de las entradas: tanto a través de designaciones individuales, como a través de producción colectiva, con la posibilidad de incluir talleres de escritura.

A pesar de que la relación entre el equipo de investigación del Diccionario de favelas y quienes lideraban los territorios se había construido con anterioridad al proyecto, lo que generó un nivel de confianza importante para el trabajo, esa diferenciación de funciones -equipo del proyecto y los líderes de las favelas- estuvo siempre presente como una tensión crítica inevitable, acerca de las relaciones de poder y jerarquías latentes. Las reuniones entre los representantes de las favelas previamente a los encuentros y a los plenarios indicaban la necesidad de mantenerse unidos en un ambiente que los diferenciaba $y$, como fue cuestionado algunas veces, los subalternizaba. La presencia cada vez mayor de miembros del equipo del Diccionario de favelas en eventos promovidos por las favelas colaboradoras fue un camino natural para que el conocimiento se generara en un ida y vuelta, con el respeto a las singularidades propias de cada contexto.

Aún con el aumento constante del número de jóvenes universitarios en las favelas, fruto de los cursos preparatorios para el examen de admisión y de las políticas de cuotas de ingreso, todavía existen adultos semianalfabetos, jóvenes con poco dominio de la escritura, que prefieren otro tipo de manifestaciones culturales. La mayoría de las y los jóvenes hacen videos y sacan fotos para registrar sus manifestaciones culturales o abusos policiales, fruto de la expansión del acceso a los celulares del tipo smartphone. Ante esta realidad, el Diccionario de favelas amplió su alcance a otras manifestaciones y lenguajes, y abrió espacio para que también se puedan producir y compartir poemas, fotografías, entrevistas y videos a través de la plataforma.

En esta segunda etapa, que privilegió la ampliación de manifestaciones y lenguajes, el Diccionario de favelas realizó una búsqueda activa de la producción de los colectivos de jóvenes que exponen sus acciones en las redes sociales. El equipo del Diccionario de favelas se dedicó, por ejemplo, a relevar materiales y datos de fuentes secundarias, de otros medios, instituciones y bancos de datos; de la propia Wikipedia y plataformas institucionales; o incluso de blogs ya reconocidos por sus trabajos sobre esta temática, como RioOnWatch. Se abrieron, así, posibilidades de nuevas colaboraciones.

A partir de un reconocimiento de ese espacio plural, el Diccionario de favelas se destaca como una oportunidad de articulación de colectivos y grupos que, desde hace décadas, vienen incentivando la movilización comunitaria en sus territorios. Como forma de dar visibilidad a los diferentes actores, colectivos, organizaciones y movimientos sociales, se los invita a compartir sus narrativas, manifiestos, films y diferentes discursos, lo que posibilita la construcción de nuevos diálogos. Políticamente, la plataforma se propone como un instrumento a disposición de la comunidad, abierto a sus diferentes formas de expresión y manifestación. Sin embargo, en qué medida realmente disputa el espacio de la narrativa hegemónica sobre las personas que habitan las favelas, es una cuestión todavía pendiente.

El Diccionario de favelas se ha dedicado a la interacción en las redes sociales con el objetivo de una aproximación cada vez mayor a las experiencias de quienes viven en las favelas y en las áreas periféricas en la producción y rescate de sus epistemologías, como también de docentes e investigadores capaces de producir y replicar los conocimientos compartidos. El sitio web donde está la plataforma y las redes, es también un espacio de disputa constante, tanto por parte de los medios comerciales como por la repercusión 
de discursos de odio amplificados por la actual crisis democrática. Es importante resaltar que, aunque Internet es abierto, el acceso no es igualitario, sino que tiene una distribución inestable en las favelas y zonas periféricas. Percibimos, por ejemplo, que la gran mayoría de los usuarios que accedieron hasta el momento lo hacen a través de celulares.

Por las restricciones impuestas por la pandemia del nuevo coronavirus en Brasil, desde marzo de 2020, las redes pasaron a ser el único espacio posible de interacción y de amplificación del propio alcance del Diccionario de favelas. Con foco en el discurso y en la comunicación, la movilización para construir colectivamente la plataforma avanzó en las redes sociales, aportando nuevos lenguajes para llegar a los diferentes públicos y sus intereses, lo que demandó la ampliación del equipo de investigadoras e investigadores con la inclusión de profesionales dedicados a las funciones de comunicación, a fin de poder difundir mejor los contenidos de la plataforma y aumentar su visibilidad.

Al sustituir la dinámica inicial de los grupos de trabajo presenciales por la movilización de colectivos a través de las redes sociales, aumentaron las interacciones y la visibilidad del Diccionario de favelas, llegando a nuevos participantes y nuevas colaboraciones, pero también significó un desplazamiento del poder hacia el equipo de investigadoras e investigadores del Diccionario de favelas, que se sintió en el consejo editorial. En sus reuniones periódicas se presentan resultados del trabajo en equipo, pero en esta nueva forma de organización, el consejo quedó sin espacio para una mayor participación de sus miembros.

\section{IR MÁS ALLÁ DE LA PLATAFORMA: LA PARTICIPACIÓN COLECTIVA EN EL ENFRENTAMIENTO DE LA PANDEMIA}

Como ya fue mencionado, el Diccionario de favelas surge en un contexto de afirmación y positivación de la identidad de la juventud de las favelas y de las zonas periféricas. Tal contexto está muy marcado por el discurso del "nosotros por nosotros" en el que líderes y colectivos reafirman la necesidad de luchar por los derechos de la población de las favelas, que incluyen no solo el derecho a la vida, sino también la voz y la memoria. Diversos grupos vienen reuniendo esfuerzos para intentar incluir en el debate público, de forma cada vez más amplia, representaciones de las favelas diferentes de aquellas presentadas por el poder público, por los grandes medios y hasta incluso por investigadores "de afuera", que presentan imágenes de estos territorios con las cuales buena parte de la población de las favelas no se identifica. El nombre de uno de los colectivos es "La favela no se calla", y expresa esa búsqueda de que la favela pueda hablar por sí misma. Impresiona el número de comunicadores de favelas que utilizan diversos medios y soportes para comunicar desde adentro de la favela.

En 2020, con la pandemia de Covid-19, el discurso del "nosotros por nosotros" ganó aún más fuerza. Cuando en marzo de 2020 la pandemia llegó a Brasil, la realidad de las poblaciones ya vulnerabilizadas sufrió impactos aún más devastadores, que refuerzan, incluso, el racismo estructural de nuestra sociedad. Ante la omisión del poder público para combatir el avance de la pandemia en las favelas, diversos grupos de habitantes de las favelas se organizaron para lidiar con los efectos de la crisis económica, sanitaria y social generada por el avance de la contaminación. Las acciones organizadas incluían la distribución de alimentos, productos de limpieza, sanitización de las favelas, registro de las familias, relevamiento de datos, etc. ${ }^{(23)}$. Esto requería de una amplia difusión de este trabajo, de manera de conseguir apoyos y recursos internos y externos para lograr su continuidad.

Como la difusión de las acciones se tuvo que realizar, principalmente, en línea, a través de las redes sociales y los medios de comunicación virtuales ya existentes, estos colectivos comenzaron a demandar el uso de la plataforma WikiFavelas para divulgar sus acciones y redes, invirtiendo así la dirección de las demandas de colaboración en la plataforma. En diálogo con colaboradores del 
proyecto, se creó en la plataforma del Diccionario de favelas un área para mapear los impactos del nuevo coronavirus en las favelas y periferias de Brasil, lo que permitió una mayor divulgación de las acciones que se realizaban en los territorios. La sección "Coronavirus en las favelas"(24), comenzó a reunir las páginas de divulgación, con información resumida abajo, relacionadas con los apoyos financieros, las noticias de los grandes medios y de los medios comunitarios sobre la pandemia en las favelas, los materiales audiovisuales sobre coronavirus producidos por y para la favela, análisis y propuestas de acciones colectivas y políticas públicas producidas por las favelas, un relevamiento de los colectivos y frentes de acción en la pandemia, paneles sobre coronavirus en las favelas, etc.

En ese contexto, surgieron nuevos desafíos para el Diccionario de favelas Marielle Franco, frente a su propuesta de construcción de un instrumento que pueda colaborar con la ampliación de las voces de las personas que habitan en las favelas, que se manifestaron de tres maneras. En primer lugar, el equipo del Diccionario de favelas comenzó a mapear e insertar información en las páginas: cómo ayudar a la población; noticias generadas por la prensa comercial y por los medios comunitarios; materiales informativos creados por los colectivos, tales como manifiestos, propuestas y planes de acción; paneles con datos de incidencia y mortalidad, etc. Posteriormente, los grupos de las favelas comenzaron a sugerir que se incluyeran sus acciones en el Diccionario de favelas. Y, por último, algunos grupos comenzaron a crear $y$ editar páginas directamente en la plataforma, lo que evidenció un cambio significativo en la forma en que los grupos de las favelas comenzaron a interactuar más activamente con el Diccionario, presentando demandas en vez de, simplemente, responder a lo que el equipo les solicitaba, como solía ocurrir con más frecuencia antes de la pandemia.

Tales movimientos definieron una tercera etapa en la trayectoria del Diccionario, que propició una articulación más intensa entre diferentes grupos de las favelas y personas de la academia que dio lugar, en el marco de la Fundação Oswaldo Cruz, a un diálogo entre líderes del Complexo do Alemão, Cidade de Deus, Complexo da Maré, Rocinha, Santa Marta, e investigadores de la Universidade Federal do Rio de Janeiro, la Pontifícia Universidade Católica-Rio y la Universidade do Estado do Rio de Janeiro. Estas nuevas articulaciones dieron como resultado un plan de acciones para el enfrentamiento del Covid-19 basado en las especificidades de las favelas. Posteriormente, bajo la conducción del Observatorio de las Metrópolis en colaboración con el Diccionario, se relevaron datos sobre los servicios públicos y los impactos de la pandemia en las favelas y zonas periféricas por medio de un cuestionario en línea. La información recolectada sirvió de base para las acciones políticas y de defensa de los derechos humanos, junto a la Defensoría Pública del Estado de Rio de Janeiro. Los resultados de ese relevamiento están disponibles en el Diccionario de favelas ${ }^{(25)}$.

Al analizar articulaciones y producciones colaborativas como la del Diccionario, Telles et al. ${ }^{(26)}$ señalan la existencia de una cadena de prácticas, mediaciones y conexiones que se establecen como capilaridades urbanas entre colectivos y redes, transformándolas en poderosas agencias productoras de informaciones, saberes y modos de conocimiento acerca de los territorios y sus poblaciones.

Se trata de una "epistemología colaborativa", que moviliza investigadores, especialistas (y sus diversas experticias), colectivos militantes, hombres y mujeres en sus contextos de vida, que activan saberes prácticos y conocimientos sobre lugares, prácticas y circunstancias cotidianas afectadas por la pandemia, y por la violencia estatal, en sus distintas modalidades. Epistemologías colaborativas o, tal vez, epistemopolíticas que se anclan en la propia vida de la ciudad y sus redes sociotécnicas, de intercambios e interacciones, también de encuentros, conexiones, convergencias y colaboraciones, formas sociopolíticas construidas, ya hace tiempo y ahora actualizadas bajo el régimen de las urgencias del momento. ${ }^{(26)}$ 
Como parte de esa "epistemología colaborativa", durante la pandemia el Diccionario comenzó a movilizar a investigadores, especialistas de diversas experticias y colectivos militantes no solo para intervenir en la plataforma, sino también más allá de ella. Habitantes, líderes e investigadores debatieron temas relacionados con: el derecho a la educación; la diversidad en las formas de vivir lo sagrado; la ayuda ante la emergencia y el derecho de ciudadanía; la salud mental en la pandemia y la violencia doméstica, el desempleo y el hambre; la movilidad y derecho a la ciudad: la favela circulando; la urbanización versus la remoción; la violencia policial en las favelas; la violencia estatal y el racismo en las favelas y las zonas periféricas; el derecho a la memoria en tiempos pandémicos; la cultura y la política. Todo ese material, grabado en video, compone un acervo único de testimonios y posicionamientos políticos sobre cómo la pandemia afecta la convivencia en las favelas, y está disponible al público en el Diccionario de favelas ${ }^{(27,28)}$.

Con esta iniciativa, se pudo ampliar la participación de los miembros del consejo editorial del Diccionario de favelas, que por ser líderes y/o investigadores con gran reconocimiento en los movimientos de las favelas, ejercieron su capacidad de convocatoria y de diálogo con los colectivos invitados, lo que permitió que las reflexiones colectivas elaboradas en ese espacio se transformaran en entradas de artículos, a partir de testimonios y análisis no solo sobre cómo se vivió la pandemia en las favelas y en las áreas periféricas, sino también cómo se potenciaron los problemas estructurales enfrentados por las poblaciones en esta coyuntura crítica. En el ámbito de los debates o epistemopolíticas se tejieron conexiones y redes sociotécnicas a partir de las vivencias y la lucha en los territorios, que liberaron la reflexión conjunta y propuestas de acción colectiva.

El Diccionario fue cobrando una dinámica que excede a la plataforma como posibilidad de almacenamiento y producción de conocimientos sobre la favela y adquiere una dimensión consistente de mediación entre sujetos políticos que disputan significados, en la lucha por la hegemonía. Laclau ${ }^{(29)}$ propone que el concepto central para comprender la hegemonía sea el de articulación o prácticas capaces de establecer equivalencias entre significados dispersos con un significante dado. Cuando es posible atribuir otros significados a un significante que parecía estar definitivo, surge la posibilidad de un cambio social.

Tal entendimiento impone una tarea adicional: no solo producir y almacenar los conocimientos en forma de artículos en la plataforma, sino ponerlos en circulación. Para ello, se hizo un esfuerzo, por un lado, para atraer visitas al Diccionario de favelas $y$, por otro, para que el contenido producido por las personas que habitan las favelas trascienda la plataforma, para lo cual se invirtió en el área de comunicación y se intensificó la presencia en las redes sociales. De esta forma, se fortaleció la estrategia de divulgación de los contenidos producidos, además de ampliar el alcance de las iniciativas y formas de organización, y el apoyo de diversos colectivos que colaboraron para enfrentar la pandemia en las favelas y en las áreas periféricas. Un uso más intensivo de las redes - Facebook, Instagram y WhatsApp- fortaleció la comunicación y difusión, además de la articulación de las colaboraciones lo que aumentó la capilaridad y materializó la propuesta de una epistemología colaborativa.

Tal materialización se dio a través de instrumentos como la construcción de un mapa de la región metropolitana de Rio de Janeiro, en el que se identifican las iniciativas de diferentes colectivos, que permite generar ingresos por donaciones. Se puede acceder al mapeo en la entrada "Cómo ayudar a las fa-

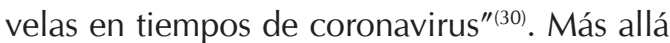
de enfrentar las carencias, participamos junto a instituciones que están también comprometidas con el mapeo de acciones que enfrentan el coronavirus en las favelas y las áreas periféricas, en la producción unificada de datos sobre la incidencia de casos y defunciones subnotificadas en las estadísticas oficiales.

La potencia que demostraron los colectivos de las favelas en la organización del espacio y las acciones colectivas, en la búsqueda de apoyos y en la denuncia de una 
ausencia de políticas adecuadas llevó incluso a la producción de datos epidemiológicos en paneles, cuya metodología fue progresivamente unificada entre la red de favelas participantes. Con la normalización de la situación de la pandemia, se puede observar una reducción significativa del apoyo que habían recibido los colectivos, en general, y las favelas y zonas periféricas, en particular. Si el inicio de la pandemia colocó a toda la sociedad en una condición de vulnerabilidad, que creó una situación de empatía y solidaridad interclases, ese efecto se va diluyendo con la normalización y el distanciamiento social entre quienes habitan en el asfalto y en la favela, progresivamente, se va restableciendo.

\section{CONSIDERACIONES FINALES}

El Diccionario de favelas puede ser entendido como un dispositivo inserto en una trama de relaciones sociales de poder con capacidad para alterarla, en la medida en que define las reglas de producción de los discursos y de la circulación de las ideas. Al no ser neutro, la imposición de ese orden será siempre una parte importante de la lucha por el poder de hablar sobre la favela y en el proceso de construcción de los sujetos que la habitan. La construcción del Diccionario de favelas Marielle Franco además de una experiencia colectiva es, por definición, inconclusa. Depende del diseño del proyecto, cuyas bases teóricas y materiales se fueron elaborando y materializando a lo largo de esa trayectoria, de los encuentros y desencuentros entre principios igualitarios y de horizontalidad en una sociedad donde imperan reglas rígidas de jerarquización y exclusión. Esta tensión es permanente y nos lleva a enfrentar las contradicciones impuestas para poder crear espacios dialógicos, que se funden en una ética de la alteridad, o sea, en el reconocimiento de que la comunicación se da entre diferentes, igualados políticamente en la condición de respetabilidad.

Confrontar los modelos de producción del conocimiento coloniales es desafiar también los poderes y contribuir a la decolonización y valorización de los saberes subalternos y periféricos, poniendo en diálogo a las constelaciones de saberes provenientes de las más diferentes experiencias sociales, sin jerarquías o discriminaciones. Este diálogo, por ejemplo, se amplía con la llegada de los "exobjetos" al mundo de la investigación académica ${ }^{(31)}$. La dinámica social y racial de la sociedad brasileña y de la academia -principal institución responsable de la producción y sociabilización del conocimiento legitimado como científico- consideró por muchos años a la población negra y de las favelas solo como objetos de investigación científica. Las políticas de acción afirmativa implementadas en la última década, a su vez, abrieron un nuevo campo de tensión epistemológica y política con el pasaje de la población negra y de las favelas desde un lugar no-hegemónico hacia lo contrahegemónico, disputando no solo los espacios sino también la propia ciencia.

En esos espacios, en que las personas subalternas tenían su palabra silenciada, aunque no de forma pasiva, los intelectuales poscoloniales, incluyendo a las propias personas subalternas, proponen viabilizar las perspectivas de grupos oprimidos ${ }^{(20)}$. De esa forma, a partir de sus propias experiencias y subjetividades, las nuevas investigaciones reconfiguran los discursos hegemónicos sobre sí mismos, sobre la historia y sobre cualquier otro aspecto de la realidad cotidiana.

Entendemos el Diccionario de favelas como una mediación, una tecnología de información que no es neutra, pero que puede ser apropiada para participar en las disputas simbólicas de poder, permitiendo aproximaciones y extrañamientos, coaliciones y enfrentamientos. De la misma forma, comprendemos que las acciones de los colectivos de las favelas, relacionados con el enfrentamiento de la pandemia, como denuncias o como producción cultural, son potencialmente políticas, porque implican la ruptura con el lugar del silencio que les fue reservado.

El surgimiento de una ciudadanía insurgente en favelas y periferias es atribuida por Holston $^{(32)}$ a la existencia de disyunciones en las democracias que no alcanzan a garantizar 
el conjunto de los derechos de ciudadanía a todos sus habitantes, en especial, a los que viven en las márgenes de las ciudades. Las polisémicas manifestaciones de esa subjetividad muestran que puede estar en curso un proceso de reconciliación entre el yo y el sujeto ${ }^{(9)}$, condición para la construcción de la memoria. Sin embargo, aún es temprano para saber en qué medida las relaciones de subordinación están siendo transformadas en relaciones de opresión, aumentando los conflictos agónicos, como propone Laclau y Mouffe ${ }^{(33)}$. Las condiciones de producción de la memoria y del habla de la persona subalterna ${ }^{(34)}$ pasarían necesariamente por ese proceso, por lo que el Diccionario de favelas, a la vez que es una tecnología social disponible para su apropiación, es un actor político comprometido en la lucha por la emancipación de la población de la favela. Inmersos en contradicciones, nuestro dispositivo navega y se reconstruye.

\section{FINANCIAMIENTO}

Este trabajo recibió apoyo de la Fundação Oswaldo Cruz.

\section{CONFLICTO DE INTERESES}

Las autoras declaran no tener vínculos o compromisos que condicionen lo expresado en el texto y que puedan ser entendidos como conflicto de intereses.

\section{REFERENCIAS BIBLIOGRÁFICAS}

1. Fleury S. Militarização do social como estratégia de integração: o caso da UPP do Santa Marta. Sociologias. 2012;14(30):194-222.

2. Amora I, Gomes M. Marielle Franco [Internet]. Dicionário de Favelas Marielle Franco; 2018 [citado 19 oct 2021]. Disponible en: https://tinyurl.com/yc8hz5wb.

3. Sartre JP. Prefacio de Jean-Paul Sartre. En: Fanon F. Os condenados da terra. Lisboa: Editora Ulisseia; 1961. p. 3-28.

4. Fanon F. Os condenados da terra. Lisboa: Editora Ulisseia; 1961.

5. Ballestrin L. América Latina e o giro decolonial. Revista Brasileira de Ciência Política. 2013;11:89-117.

6. Foucault M. Nascimento da biopolítica: Curso dado no Collège de France (1978 - 1979). São Paulo: Martins Fontes; 2008.

7. Quijano A. Colonialidade do poder, eurocentrismo e América Latina. En: Lander E, (org.). A colonialidade do saber: eurocentrismo e ciências sociais, perspectivas latino-americanas. Buenos Aires: CLACSO; 2005. p. 117 142.
8. Queiroz M. A sociologia militante de Guerreiro Ramos. Jacobin Brasil [Internet]. 2020 [citado 24 oct 2020]. Disponible en: https://tinyurl.com/2p89kb9h.

9. Mbembe A. Crítica da razão negra. Lisboa: Editora Antígona; 2018.

10. Santos BS, Meneses MP. (org.). Epistemologias do sul. Coimbra: Almedina; 1995.

11. Santos BS. Pela mão de Alice: o social e o político na pós-modernidade. São Paulo: Cortez Editora; 1995.

12. Araujo B. Lélia Gonzalez, intérprete do capitalismo brasileiro. Jacobin Brasil [Internet]. 2020 [citado 24 oct 2020]. Disponible en: https://tinyurl.com/36xverf2.

13. Galindo M. No se puede descolonizar sin despatriarcalizar: Teoría y propuesta de la despatriarcalización. Bolivia: Mujeres Creando; 2013.

14. Bourdieu P. A dominação masculina. 11a ed. Rio de Janeiro: Bertrand Brasil; 2012.

15. Fleury S. Democracia e socialismo: o lugar do sujeito. En: Fleury S, Lobato L. (org.). Participação, democracia e saúde. Rio de Janeiro: Cebes; 2009. p. 24-46.

16. D'Andrea TP. A formação dos sujeitos periféricos: cultura e política na periferia de São Paulo. [Tese de Doutorado]. São Paulo: Programa de Pós-Graduação em Sociologia, Universidade de São Paulo; 2013.

17. Krapp J. Lançamento do Dicionário de Favelas Marielle Franco [Internet]. 2019 [citado 19 oct 2021]. Disponible en: https://tinyurl.com/4fwvbpnr.

18. Esteves B, Cukierman HL. A controvérsia sobre as causas do aquecimento global em 15 artigos da Wikipédia lusófona. Seminário Nacional de História da Ciência e da Tecnologia, 2012 [citado 15 nov 2020] Disponible en: https://tinyurl.com/4d9vjzew. 
19. Marteleto R, Couzinet V. Mediações e dispositivos de informação e comunicação na apropriação de conhecimentos: elementos conceituais e empíricos a partir de olhares intercruzados. Revista Eletrônica de Comunicação, Informação e Inovação em Saúde. 2013;7(2). doi: 10.3395/reciis.v7i2.810pt.

20. Kilomba G. Memórias da plantação: Episódios de racismo cotidiano. Rio de Janeiro: Editora Cobogó; 2019.

21. Spivak G. Pode o subalterno falar? Belo Horizonte: Editora UFMG; 2014.

22. Carneiro SA. Construção do outro como não-ser como fundamento do ser. [Tese de Doutorado]. São Paulo: Programa de Pós-Graduação em Educação, Universidade de São Paulo; 2005.

23. Fleury S, Menezes PV. Pandemia nas favelas: entre carências e potências. Saúde em Debate. 2020;44(Esp. 4):267-280

24. Coronavirus nas favelas [Internet]. 2021 [citado 19 oct 2021]. Disponible en: https://tinyurl.com/3j876bjx.

25. Resultados - Covid-19 nas favelas [Internet]. 2020 [citado 19 oct 2021]. Disponible en: https://tinyurl. com/42axded3.

26. Telles $\mathrm{V}$, et al. (Micro) politicas da vida em tempos de urgência. Labcidade [Internet]. 2020 [citado 19 oct 2021]. Disponible en: https://tinyurl.com/27du2jzn.
27. Favelas, Pandemias e Cidadanias [Internet]. 2021 [citado 19 oct 2021]. Disponible en: https://tinyurl.com/yckkynxm.

28. Favelas em Movimento [Internet]. 2021 [19 oct 2021] Disponible en: https://tinyurl.com/23wxyapa.

29. Laclau E. Prólogo. En: Anderson P. La cultura represiva: Elementos de la cultura britânica. Barcelona: Anagrama; 1977. p. 5-21.

30. Apoie as favelas na luta contra o Coronavirus [Internet]. 2021 [citado 19 oct 2021]. Disponible en: https:// tinyurl.com/3rvskury.

31. Gomes N. Intelectuais negros e produção do conhecimento: algumas reflexões sobre a realidade brasileira. En: Santos BV, Meneses MP, (org.). Epistemologias do Sul. Coimbra: Editora Almedina; 2009. p. 419-442

32. Holston J. Cidadania insurgente: disjunções da democracia e da modernidade no Brasil. São Paulo: Companhia das Letras; 2013.

33. Laclau E, Mouffe C. Hegemonía y estrategia socialista. Madrid: Siglo XXI Editores; 1987.

34. Spivak G. Pode o subalterno falar? Belo Horizonte: Editora UFMG; 2014.

FORMA DE CITAR

Fleury S, Polycarpo C, Menezes P, Fornazin M. El desafío de la descolonización del conocimiento: el Diccionario de favelas Marielle Franco. Salud Colectiva. 2022;18:e3850. doi: 10.18294/sc.2022.3850.

Recibido: 19 oct 2021 | Aprobado: 16 dic 2021 | Publicado en línea: 25 ene 2022

Esta obra está bajo una licencia Creative Commons Atribución 4.0 Internacional (CC BY 4.0). Atribución - Se debe dar crédito de manera adecuada, brindar un enlace a la licencia, e indicar si se han realizado cambios. Puede hacerlo en cualquier forma razonable, pero no de forma tal que sugiera que usted o su uso tienen el apoyo de la licenciante. Sin restricciones adicionales - No se pueden aplicar términos legales ni medidas tecnológicas que restrinjan legalmente a otras personas a hacer cualquier uso permitido por la licencia. 